\section{Ondansetron is a better prophylactic antiemetic than droperidol for ton- sillectomy in children}

William M. Splinter MD FRCPC,

Elliot J. Rhine MBChB FRCPC, David W. Roberts MD FRCPC, Michael R.N. Baxter MB FRCA, H. Marion Gould MD FRCPC, Leslie E. Hall MD FRCPC, Helen B. MacNeill MD FRCPC
Both intravenous ondansetron (OND) and droperidol (DROP) have been observed to reduce vomiting after tonsillectomy in children. This randomized, double-blind investigation compared the effect of OND and DROP on vomiting after outpatient tonsillectomy in 276 healthy children age 2-12 yr. All subjects received a standardized anaesthetic, which consisted of induction with either propofol or halothane $/ \mathrm{N}_{2} \mathrm{O}$, vecuronium $0.1 \mathrm{mg} \cdot \mathrm{kg}^{-1}$ on an as needed basis, maintenance with halothane $/ \mathrm{N}_{2} \mathrm{O}$, midazolam and codeine, and reversal of neuromuscular blockade with neostigmine and atropine on an as needed basis. Subjects were given either OND $150 \mu \mathrm{g} \cdot \mathrm{kg}^{-1}$ or DROP $50 \mu \mathrm{g} \cdot \mathrm{kg}^{-1} \mathrm{iv}$ afier induction of anaesthesia. Rescue antiemetics in the hospital were administered to patients who vomited $\times 2$ and $\times 4$, respectively. Postoperative pain was treated with morphine, codeine and/or acetaminophen. For 24 hr following surgery, emesis was recorded by nursing staff while subjects were in hospital, and by parents following discharge from hospital. The two groups were similar with respect to demographic data, induction technique and anaesthesia time. The frequency of in-hospital emesis was $16 \%$ in the OND-patients and $30 \%$ in the DROP-group, $P<0.05$. The OND-subjects required fewer rescue antiemetics, $5 \%$ vs $13 \%, P<0.05$. The overall incidence of emesis was $45 \%$ in the OND-group and $57 \%$ in the DROP-group, $P<0.05$. In conclusion, ondansetron was a superior prophylactic antiemetic for tonsillectomy in children when compared to droperidol.

\section{Key words}

ANAESTHESIA: paediatric, outpatient;

SURGERY: tonsillectomy;

VOMITING: postoperative, ondansetron, droperidol.

From the Department of Anaesthesia, Children's Hospital of Eastern Ontario, University of Ottawa, Ottawa, Ontario, Canada, K1H 8Ll

Address correspondence to: Dr. William Splinter, Department of Anaesthesia, Children's Hospital of Eastern Ontario, 401 Smyth Rd., Ottawa, Ontario, Canada, K1H 8L1. Accepted for publication 28th May, 1995.
L'ondansetron (OND) et le dropéridol (DROP) sont reconnus pour diminuer les vomissements après l'amygdalectomie chez l'enfant. Cette investigation aléatoire et à double insu compare l'efficacité de l'OND et du DROP contre les vomissements de 276 enfants de 2 à 12 ans opérés pour une amygdalectomie en chirurgie ambulatoire. Tous les sujets reçoivent une anesthésie standardisée, qui comprend une induction au propofol ou à l'halothane $/ \mathrm{N}_{2} \mathrm{O}$, avec vécuronium $0,1 \mathrm{mg} \cdot \mathrm{kg}^{-l}$ au besoin, un entretien à lhalothane $\mathrm{N}_{2} \mathrm{O}$, midzolam et codéine et une décurarisation avec néostigmine et atropine lorsque jugée nécessaire. Les sujets reçoivent OND $150 \mu \mathrm{g} \cdot \mathrm{kg}^{-1}$ ou DROP $50 \mu \mathrm{g} \cdot \mathrm{kg}^{-1}$ iv après linduction. Un antiémétique de sauvetage est administré à lhôpital aux patients qui vomissent deux et quatre fois, respectivement. La douleur postopératoire est traitée avec de la morphine, de la codéine avec ou sans acétaminophène. Vingt-quatre heures après la chirurgie, les vomissements sont enregistrés par le personnel infirmier lorsque que les enfants sont encore hospitalisés, ou par les parents par la suite. Les deux groupes sont comparables quant aux données démographiques, à la technique d'induction à la durée de l'anesthésie. La fréquence des vomissements pendant lhospitalisation est de $16 \%$ chez les patients du groupe OND et de $30 \%$ du groupe DROP, $P<0,05$. Les sujets du groupe OND ont besoin de moins souvent diun antiémétique de sauvetage, $5 \%$ vs $13 \%$. $P<0,05$. Lincidence globale des vomissements est de $45 \%$ dans le groupe OND et de 57\% dans le groupe DROP, $P<$ 0,05. Pour conclure, l'ondansetron est supérieur au dropéridol comme antiémétique après l'amygdalectomie chez les enfants.

As many as $75 \%$ of children vomit after general anaesthesia for tonsillectomy. ${ }^{1}$ Vomiting may lead to delays in hospital discharge and occasionally may require unscheduled admission to hospital. This represents a considerable burden to patients, parents and health care system. To overcome this, anaesthetic techniques and antiemetics that will minimize vomiting after tonsillectomy are desirable.

The most effective prophylactic antiemetic available is unknown, but we believe that it is either droperidol (DROP) or ondansetron (OND). Both ondansetron and droperidol have been shown to decrease vomiting after 
tonsillectomy in children. ${ }^{2,3}$ Droperidol has important, relatively common adverse effects, including excess sedation and extrapyramidal symptoms (involuntary muscle contractures). Droperidol has been observed to decrease vomiting after tonsillectomy in children from $71 \%$ to $46 \%{ }^{2}$ Ondansetron is an expensive, recently released atternative with fewer and less-severe adverse effects. Compared with placebo, intravenous ondansetron decreased the incidence of vomiting from $73 \%$ to $23 \%$ after tonsillectomy in children. ${ }^{3}$ Side effects after ondansetron are rare. ${ }^{4}$ Among adults, preoperative prophylactic administration of ondansetron is superior to droperidol in the prevention of vomiting after general anaesthesia. ${ }^{5}$ The current study was therefore initiated to determine whether ondansetron was a superior prophylactic antiemetic to droperidol when used in children undergoing tonsillectomy.

\section{Methods}

Following Hospital Ethics Committee approval and written parental consent, we studied 276 healthy children age 2-12 years scheduled to undergo elective tonsillectomy or adenotonsillectomy. Subjects were excluded if they had a study-drug allergy.

After placement of routine monitors, anaesthesia was induced by mask with halothane $/ \mathrm{N}_{2} \mathrm{O}$ or $\dot{v}$ with propofol $2.5 \mathrm{mg} \cdot \mathrm{kg}^{-1}$ mixed with lidocaine $0.5 \mathrm{mg} \cdot \mathrm{kg}^{-1}$. Vecuronium $0.1 \mathrm{mg} \cdot \mathrm{kg}^{-1}$ was administered to facilitate tracheal intubation at the discretion of the individual anaesthetist. Patients were given droperidol $50 \mu \mathrm{g} \cdot \mathrm{kg}^{-1}$ or ondansetron $150 \mu \mathrm{g} \cdot \mathrm{kg}^{-1} i \mathrm{i}$ in a double-blind randomized fashion after induction of anaesthesia. Anaesthesia was maintained with halothane $/ \mathrm{N}_{2} \mathrm{O}$, midazolam 50 $\mu \mathrm{g} \cdot \mathrm{kg}^{-1} \dot{i}$ and codeine $1-1.5 \mathrm{mg} \cdot \mathrm{kg}^{-1} \mathrm{im}$. At the conclusion of surgery, residual neuromuscular blockade was reversed with atropine $20 \mu \mathrm{g} \cdot \mathrm{kg}^{-1}$ and neostigmine 60 $\mu \mathrm{g} \cdot \mathrm{kg}^{-1}$. Orogastric tubes were not used. Postoperatively, patients were offered clear fluids in the Day Care Surgical Unit (DCSU) only if the child requested a drink. Rescue antiemetics in the hospital were $1 \mathrm{mg} \cdot \mathrm{kg}^{-1} \mathrm{di}-$ menhydrinate $i v$ for vomiting (not retching) $\geq 2$ and droperidol $50 \mu \mathrm{g} \cdot \mathrm{kg}^{-1}$ for vomiting $\geq 4$. All episodes of in-hospital emesis were recorded by nursing staff. Parents kept a diary of emesis for $24 \mathrm{hr}$ after surgery. On the day after surgery, the parents were contacted by a research assistant and reminded to mail their diary. Postoperative pain was treated with morphine $50 \mu \mathrm{g} \cdot \mathrm{kg}^{-1}$ in the post-anaesthesia recovery room (PAR) and codeine $1 \mathrm{mg} \cdot \mathrm{kg}^{-1}$ and/or acetaminophen $10-15 \mathrm{mg} \cdot \mathrm{kg}^{-1}$ in the DCSU and at home. Patients were discharged from DCSU, if after a minimum four-hour stay, they were not nauseated, had little or no pain, were ambulatory and were not actively bleeding.
Data were compared with one-way ANOVA for continuous variables and Chi-square analysis for dichotomous variables. For sample size determination and significance testing, the accepted alpha and beta errors were 0.05 and 0.20 , respectively. The predicted incidence of vomiting was $40 \%$ in the droperidol group and $25 \%$ in the ondansetron group.

\section{Results}

The groups were similar with respect to demographic data, anaesthesia time and intraoperative blood loss (Table I). Seventy-eight patients (28\%) underwent $\dot{w}$ induction, of whom $44(56 \%)$ received droperidol.

In-hospital pain management was similar. Thirty-one and 35 patients in DROP and OND groups, respectively, received morphine in the PAR. Before discharge from hospital codeine $1 \mathrm{mg} \cdot \mathrm{kg}^{-1}$ was given po or im to $76 \%$ and $80 \%$ of the DROP and OND-patients, respectively.

Patients vomited from 0-16 times during the $24 \mathrm{hr}$ after surgery (Figure) with a lower incidence of emesis among the ondansetron patients (Table II). This was especially true in hospital, where only $16 \%$ of the ONDgroup vomited, while $30 \%$ of the DROP-group vomited, $P<0.05$, Chi-square analysis. This beneficial effect persisted during the day of surgery, such that, during the day of tonsillectomy $33 \%$ of the OND-patients and $52 \%$ of the DROP-group vomited, $P<0.05$. Rescue antiemetics were required less often by the ondansetron-treated patients (Table II). Two patients in the DROP-group vomited four or more times in-hospital. With each episode of in-hospital vomiting, discharge was delayed by $12 \pm$ 2 min (mean $\pm S D$ ), $P<0.001$. One patient in the DROP-group was admitted after surgery because of vomiting. Also, two patients in the OND-group returned to hospital the day after surgery because of emesis. One patient in each group was admitted to hospital because of persistent bleeding after tonsillectomy. The incidence of vomiting was not affected by induction technique with emesis rates of $22 \%$ and $23 \%$ in hospital and $47 \%$ and $52 \%$ overall in children whose anaesthesia was induced by $i v$ and inhalation, respectively.

\section{Discussion}

The present study compared two established and effective approaches in the prevention of vomiting after tonsillectomy in children. Ondansetron $150 \mu \mathrm{g} \cdot \mathrm{kg}^{-1}$ decreased the incidence of vomiting more effectively during the first day of surgery, but there was no difference in the incidence of vomiting during the day after discharge from hospital.

The observed incidence of vomiting is comparable with the $12-75 \%$ previously noted. ${ }^{1,6}$ Direct comparison with other investigations is difficult, because there is no con- 
TABLE I Patient characteristics

\begin{tabular}{|c|c|c|c|c|c|c|c|}
\hline Group & $n$ & $\begin{array}{l}\text { Age } \\
(y r)\end{array}$ & $\begin{array}{l}\text { Weight } \\
(\mathrm{kg})\end{array}$ & $\begin{array}{l}E B L \\
(m l)\end{array}$ & $\begin{array}{l}\text { Anaes. } \\
\text { time } \\
\text { (min) }\end{array}$ & $\begin{array}{l}P A R \\
\text { time } \\
\text { (min) }\end{array}$ & $\begin{array}{l}\text { Time to } \\
\text { discharge } \\
\text { (hr) }\end{array}$ \\
\hline $\begin{array}{l}\text { DROP } \\
\text { OND }\end{array}$ & $\begin{array}{l}136 \\
140\end{array}$ & $\begin{array}{l}7.3 \pm 3.0 \\
7.1 \pm 3.0\end{array}$ & $\begin{array}{l}28 \pm 13 \\
27 \pm 14\end{array}$ & $\begin{array}{l}36 \pm 39 \\
37 \pm 44\end{array}$ & $\begin{array}{l}36 \pm 14 \\
37 \pm 13\end{array}$ & $\begin{array}{l}49 \pm 19 \\
46 \pm 14\end{array}$ & $\begin{array}{l}4.1 \pm 0.4 \\
3.9 \pm 0.4^{*}\end{array}$ \\
\hline
\end{tabular}

Mean $\pm \mathrm{SD}, \mathrm{DROP}=$ droperidol, $\mathrm{OND}=$ ondansetron, $\mathrm{EBL}=$ estimated intraoperative blood loss, PAR $=$ post-anaesthetic recovery room. $* P=0.025$.

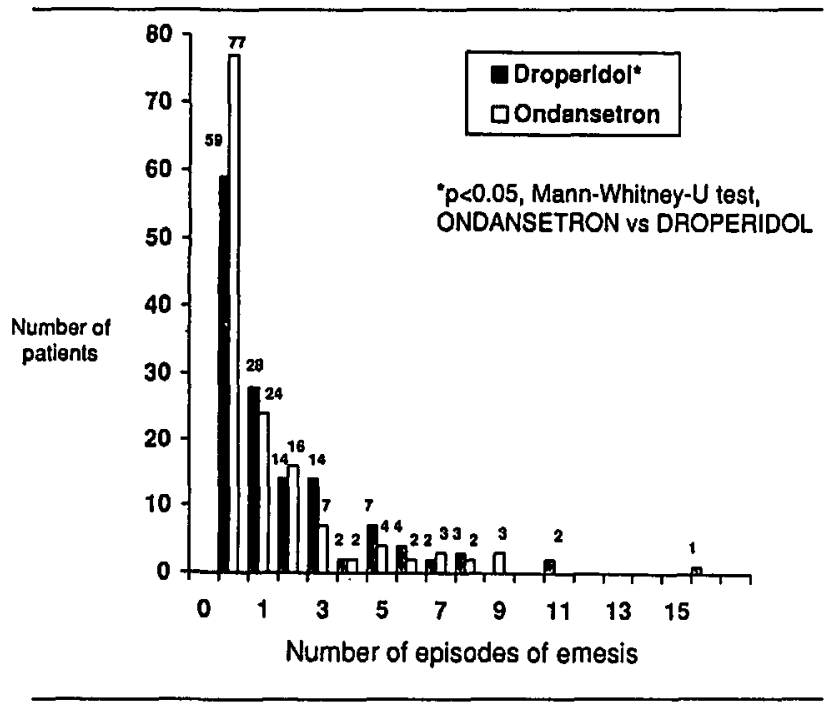

FIGURE The distribution of patients with 0-16 emetic episodes among the two groups.

sistent follow-up time period. The in-hospital vomiting rate was similar to the $26 \%$ observed after prophylactic ondansetron by Stene et al. ${ }^{7}$ and the $8-23 \%$ observed by Rose $e t$ al. after ondansetron administration. ${ }^{8}$.

In our study, subjects experienced a need for rescue antiemetics of 5-13\%, which is less than the $26-48 \%$ observed by Grunwald et al. ${ }^{2}$ Rose et al. noted a requirement for rescue antiemetics of 3-40\% among the children they studied, but their OND-treated patients only had a 3-5\% rate, which is similar to the current observations. ${ }^{8}$ Induction of anaesthesia with propofol did not alter postoperative vomiting, which is consistent with previous investigations. ${ }^{8,9}$

The effect of both prophylactic antiemetics is limited. By the day after surgery the incidence of vomiting was surprisingly high and similar among the groups studied. This increased our observed incidence of vomiting to values much greater than expected. More importantly, in two of our patients this vomiting was so severe that the child required medical attention at a local hospital emergency department. There have been no investigations
TABLE II Vomiting incidence

\begin{tabular}{lllllll}
\hline & Vomit & \multicolumn{3}{l}{ Vomit by location $\%$} & & $\begin{array}{l}\text { Rescue } \\
\text { Group }\end{array}$ \\
\cline { 2 - 6 } & $\%$ & PAR & DCSU & Day 0 & Day I & $\%$ \\
\hline DROP & $57^{*}$ & 2 & $30^{*}$ & $36^{*}$ & 24 & $13^{*}$ \\
OND & 45 & 1 & 15 & 21 & 26 & 5 \\
\hline
\end{tabular}

${ }^{*} P<0.05$. Chi-square or Fisher Exact Test.

of vomiting on the day after tonsillectomy. Thus, the aetiology and treatment of this phenomenon are unknown. A possible solution to the delayed vomiting would be an antiemetic with prolonged action. The lack of prolonged effect is not consistent with Watcha $e t$ al. and Grunwald et al. who observed an extended clinical antiemetic effect after ondansetron and droperidol, respectively, in children. ${ }^{2,4}$

The dose of ondansetron used during the current study was based on that of Litman. ${ }^{3}$ It has been recommended that a lower, much less expensive dose of $50 \mu \mathrm{g} \cdot \mathrm{kg}^{-1}$ of ondansetron would also be effective. ${ }^{4}$

Although we have observed that ondansetron in a dose of $150 \mu \mathrm{g} \cdot \mathrm{kg}^{-1}$ is a more effective antiemetic than droperidol, other considerations, such as financial implications and side-effect profiles will play an important role in deciding whether or not an antiemetic is utilized. ${ }^{10}$ Ondansetron is an efficacious antiemetic which is several times more expensive than droperidol. (At our hospital the 3 $\mathrm{mg} \dot{i v}$ dose of ondansetron cost is $\$ 12.90$, compared with $\$ 1.17$ for a similar dose (1 mg) of droperidol.) The use of ondansetron would increase our hospital pharmacy budget, but savings could reside in the nursing budget. Unfortunately, within our health care system these savings are extremely difficult to assess. Even more complex is the monetary value to the parents of an improved perioperative course. Finally, we must ask are there any longterm savings to the child if the perioperative course is less traumatic? Future investigations would need to address these expenses and savings in a fashion that is relevant to all care givers within the Canadian health care system. 
In summary, the current investigation demonstrated that a single dose of $150 \mu \mathrm{g} \cdot \mathrm{kg}^{-1}$ of ondansetron given intraoperatively more effectively reduces vomiting after tonsillectomy in children than droperidol. The effectiveness of both ondansetron and droperidol given as a single intravenous dose is limited to less than 24 hours postoperatively.

\section{Acknowledgements}

We thank our colleagues in Otolaryngology and Nursing for their cooperation and advice during this study. We also wish to thank Ms. Marilyn Birnie, Ms. Tina Subissati, Ms. Lydia Komocar and Ms. Colline Blanchard for their vital help in conducting this investigation.

\section{References}

1 Pandit U, Pryn S, Randel G, Levy L, Lewis I. Nitrous oxide does not increase postoperative nausea/vomiting in pediatric outpatients undergoing tonsillectomy-adenoidectomy. Anesthesiology 1990; 73: A1245.

2 Grunwald Z, Schreiner MS, Parness J, Potsic WP, Templeton JJ. Droperidol decreases the incidence and the severity of vomiting after tonsillectomy and adenoidectomy in children. Paediatric Anaesthesia 1994; 4: 163-7.

3 Litman RS, Wu CL, Catanzaro FA. Ondansetron decreases emesis after tonsillectomy in children. Anesth Analg 1994; 78: 478-81.

4 Watcha MF, Bras PJ, Cieslak GD, Pennant JH. The dose-response relationship of ondansetron in preventing postoperative emesis in pediatric patients undergoing ambulatory surgery. Anesthesiology 1995; 82: 47-52.

5 Alon E, Himmelseher $S$. Ondansetron in the treatment of postoperative vomiting: a randomized, double-blind comparison with droperidol and metoclopramide. Anesth Analg 1992; 75: 561-5.

6 Grunwald Z, Guarnieri K, Torjman M. Comparison of the antiemetic effect of I.V. droperidol given in the PACU versus a double dose regimen in children having tonsillectomy and adenoidectomy. Anesth Analg 1992; 74: S124.

7 Stene EN, Bostrom BC, Seay RE, Young LA, Bohnsack $L E$. The antiemetic efficacy of prophylactic ondansetron in pediatric tonsillectomy and adenoidectomy patients. Anesthesiology 1994; 81: A1353.

8 Rose J, Dooley M, Martin T. A comparison of the antiemetic efficacy of one or two doses of metoclopramide or ondansetron in children undergoing tonsillectomy. Anesthesiology 1994; 81: A1352.

9 Splinter WM, Baxter MRN, Gould HM, et al. Oral ondansetron decreases vomiting after tonsillectomy in children. Can J Anaesth 1995; 42: 277-80.

10 Lerman J. Are antiemetics cost-effective for children? (Editorial) Can J Anaesth 1995; 42: 263-6. 